\title{
Substitution of night-time continuous subcutaneous insulin infusion therapy for bedtime NPH insulin in a multiple injection regimen improves counterregulatory hormonal responses and warning symptoms of hypoglycaemia in IDDM
}

\author{
K. Kanc, M. M. J.Janssen, E. T. P. Keulen, M. A.J.M.Jacobs, C. Popp-Snijders, F. J. Snoek, R.J. Heine \\ Research Institute for Endocrinology, Reproduction and Metabolism \\ Department of Endocrinology, 'Vrije Universiteit' Hospital, Amsterdam, The Netherlands
}

\begin{abstract}
Summary In patients with insulin-dependent diabetes mellitus (IDDM) good glycaemic control confers an enhanced risk of hypoglycaemia. Nocturnal hypoglycaemia occurs frequently and contributes to the syndrome of hypoglycaemia unawareness. In order to avoid nocturnal hypoglycaemia we substituted night-time continuous subcutaneous insulin infusion (CSII) therapy in 14 patients with well-controlled IDDM using a multiple injection regimen for the more variable bedtime NPH insulin. During a stepwise hypoglycaemic clamp we studied the effect of this regimen on counterregulatory hormonal responses, warning symptoms and cognitive function. In addition, we investigated the incidence of daytime hypoglycaemia and the acceptability of night-time CSII treatment. CSII was associated with a lower frequency of hypoglycaemia (mean \pm SEM): $16.1 \pm 3.1$ vs $23.6 \pm 3.3$ ) episodes during the last 6 weeks of treat-
\end{abstract}

ment, $p=0.03$ (CSII vs NPH)) with maintenance of good glycaemic control $\left(\mathrm{HbA}_{1 \mathrm{c}} 7.2 \pm 0.2\right.$ vs $7.1 \pm 0.2 \%, p=0.2$ ). Hypoglycaemic thresholds for the growth hormone response and for autonomic symptoms were lower for CSII treatment than for NPH treatment. Of 14 patients 6 decided to continue with the nocturnal CSII treatment. In conclusion, nocturnal CSII improves warning symptoms and counterregulatory hormonal responses to hypoglycaemia and is an acceptable treatment strategy for patients suffering from hypoglycaemia unawareness, as demonstrated in this acute feasibility study. [Diabetologia (1998) 41: 322-329]

Keywords Nocturnal hypoglycaemia, night-time CSII, hypoglycaemia unawareness, strategy against hypoglycaemia.
Several recent studies have demonstrated that good glycaemic control reduces the risk of late diabetic complications such as retinopathy, nephropathy and neuropathy [1-3]. However, maintenance of good glycaemic control considerably increases the incidence of all degrees of hypoglycaemia [4]. The magnitude of this increase has been shown to be closely re-

Received: 21 July 1997 and in revised form: 7 October 1997

Corresponding author: Professor R. J. Heine, M. D., Vrije Universiteit Amsterdam, Department of Endocrinology, de Boelelaan 1117, NL-1081 HV Amsterdam, The Netherlands Abbreviations: IDDM, Insulin-dependent diabetes mellitus; CSII, continuous subcutaneous insulin infusion; CR hormonal response, counterregulatory hormonal response; NPH insulin, neutral protamin Hagedorn insulin. lated to the achieved level of glycaemic control [4]. In patients with a diabetes duration of more than 15 years, in patients with strict glycaemic control and in those who previously experienced a severe hypoglycaemia blunted counterregulatory hormonal responses [5, 6] and absence of autonomic warning symptoms to hypoglycaemia have been reported [7]. Hypoglycaemia unawareness, i. e. the inability to perceive consciously the onset of hypoglycaemia, may, among other factors, be induced by even mild episodes of hypoglycaemia, including nocturnal hypoglycaemia [8-10]. In well-regulated insulin-dependent diabetic (IDDM) patients nocturnal hypoglycaemia occurs once every 2-3 nights [11] and this incidence rate might even be an underestimation [12]. Probably the high incidence of nocturnal hypoglycaemia is mainly a consequence of the characteristics of the 
depot insulins, which have a highly variable absorption rate from the subcutaneous tissue [13-15] and a peak insulin activity at a time when insulin requirements are declining [16]. Meticulous prevention of hypoglycaemia has been shown to improve the counterregulatory hormonal responses and warning symptoms of hypoglycaemia [17]. Notwithstanding the importance of these findings it is difficult to implement the applied method to stabilize blood glucose control in daily practice. In our study we assessed the influence of a more stable nocturnal blood glucose control on the counterregulatory hormonal responses and symptoms of hypoglycaemia. For this purpose we replaced the bedtime injection of intermediate-acting insulin with night-time continuous subcutaneous insulin infusion (CSII) treatment. The variability of insulin absorption with CSII has been shown to be lower than with intermediate-acting insulin [18-21]. Moreover, CSII with programmable basal infusion rates is able to cope with varying nocturnal insulin requirements and can therefore establish a stable overnight plasma glucose profile [22]. We studied the autonomic and neuroglycopenic warning symptoms, the counterregulatory hormonal responses and the cognitive function in IDDM patients with self-reported hypoglycaemia unawareness during a standardized hyperinsulinaemic hypoglycaemic clamp. Furthermore, we assessed the acceptability of this treatment regimen as well as its influence on the incidence rate of symptomatic hypoglycaemia.

\section{Subjects, materials and methods}

Subjects. Fifteen IDDM patients were recruited for this study. They had to fulfil the following criteria:

1) Inability to perceive autonomic hypoglycaemic warning symptoms for at least 6 months prior to the study and/or a history of severe hypoglycaemia in the past year.

2) Absence of autonomic neuropathy as assessed with two cardiovascular autonomic nervous function tests: variation in heart rate during deep breathing and heart rate responses to standing after 5 min supine rest [23].

3) Good glycaemic control $\left(\mathrm{HbA}_{1 \mathrm{c}}<8.5 \%\right.$, reference range 4.3-6.1\%) and multiple insulin injection therapy (three or more injections of regular insulin daily, intermediate-acting insulin (Neutral Protamin Hagedorn, NPH) at bedtime).

Only 2 patients had manifestations of mild complications: 1 patient had background retinopathy and one patient had microalbuminuria. One of the 15 patients had to be excluded because of pregnancy. Patient characteristics are presented in Table 1 . A healthy, non-diabetic control group of 12 volunteers, matched for age and body mass index, was studied for the assessment of physiological responses to hypoglycaemia (Table 1). The healthy subjects took part in another study the results of which have been reported elsewhere [24]. All subjects gave written informed consent prior to the study. The protocol was approved by the local ethical committee and the study was conducted in accordance with the Helsinki Declaration.
Table 1. Clinical and laboratory characteristics of patients and healthy subjects

\begin{tabular}{lll}
\hline & IDDM patients & Healthy subjects \\
\hline$n$ & 14 & 12 \\
Male/female & $13 / 1$ & $12 / 0$ \\
Age (years) & $31.5(20-45)$ & $25.0(20-28)$ \\
Body mass index $\left(\mathrm{kg} / \mathrm{m}^{2}\right)$ & $23.2(19.5-26.0)$ & $21.9(20.1-24.5)$ \\
Diabetes duration (years) & $12.5(7-20)$ & $/$ \\
HbA $_{1 \mathrm{c}}(\%)$ & $7.4(6.0-8.7)$ & $/$ \\
$\begin{array}{l}\text { (reference range: } 4.3-6.1 \%) \\
\begin{array}{l}\text { No. of persons with episodes } \\
\text { of severe hypoglycaemia }\end{array}\end{array}$ & $7 / 14$ & \\
$\begin{array}{l}\text { (at least one in the preceding } \\
\text { year) }\end{array}$ & & \\
\hline
\end{tabular}

Data are median (range)

Study protocol. The study had an open, randomized, cross-over design. During a 2-week run-in period, the insulin treatment was stabilized and patients became familiar with frequent home blood glucose measurements (i.e. daily fasting and at bedtime and twice weekly in addition, before and $2 \mathrm{~h}$ after each main meal and between 03.00 and 04.00 hours) with reflectometer-read strips. All patients used the same glucometers and were advised to write down their readings in standardised diaries.

Following the run-in period patients were randomly allocated to either of the two therapy groups. In one group patients' own regimen with three or more short-acting insulin injections during the day and NPH at bedtime was continued, while in the other group the bedtime NPH was replaced by night-time CSII treatment (Hoechst Infusor V100 pump; Disetronic, Burgdorf, Switzerland). After 2 months the patients crossed over to the other regimen. The NPH dose was adjusted according to the bedtime, 03.00 hours and fasting home blood glucose readings of the first treatment period week. The target blood glucose values were between 4.0 and $8.0 \mathrm{mmol} / \mathrm{l}$ before meals and at 03.00 hours and between 8 and $10 \mathrm{mmol} / \mathrm{l}$ at bedtime. The CSII basal rate was determined by the investigator according to the bedtime, 03.00 hours and fasting home blood glucose readings of the first treatment period week on CSII. In some patients, where the dawn phenomenon was present, two or more basal infusion rates were applied in order to achieve a stable nocturnal blood glucose profile. The CSII therapy started between 22.00 and 23.00 hours. After placing the catheter in the abdominal subcutaneous tissue a 2 IU bolus of insulin was administered, followed by the continuous infusion of the individual basal infusion rate (range: $0.4-1.0 \mathrm{U} / \mathrm{h}$ ). CSII was discontinued following the administration of the usual pen-device injection of the short-acting insulin before breakfast. The daytime regimen remained unaltered. Insulin dosages were adjusted whenever required. During both treatment periods patients recorded the severity and type of warning symptoms during a hypoglycaemic episode (defined as a measured blood glucose value lower than $3.5 \mathrm{mmol} / \mathrm{l}$ with or without symptoms) according to a modified, standardized questionnaire, attached to a diabetes diary [24, 25]. At the end of the study patients' assessment of the new therapeutic regimen was made in terms of perceived burden and satisfaction.

Methods. At the end of each treatment period a standardized, step-wise hyperinsulinaemic hypoglycaemic clamp was performed, as previously described [26]. Patients were admitted to the research unit at 21.00 hours the evening prior to the 
test after strictly avoiding hypoglycaemia for at least $24 \mathrm{~h}$ by frequent home blood glucose monitoring and abstaining from vigorous exercise. Three intravenous cannulae were inserted: one for all infusions into one antecubital vein, the second in the antecubital vein of the contralateral arm for sampling of venous blood for hormone measurements, and a third retrogradely into a dorsal hand vein. This hand was placed in a plexiglass box heated with air to approximately $60^{\circ} \mathrm{C}$ for sampling of arterialized venous blood [27] for frequent measurement of blood glucose concentration. That evening no intermediate-acting insulin was administered. Blood glucose values were kept between 5.5 and $10.0 \mathrm{mmol} / \mathrm{l}$ overnight by an intravenous human insulin infusion (Velosulin; Novo Nordisk Bagsvaerd, DK). Healthy volunteers were admitted to the research unit at 07.00 hours after an overnight fast from 22.00 hours the evening before. After the insertion of the cannulae they rested for at least $30 \mathrm{~min}$ before the test started. Insulin (42 IU: $0.42 \mathrm{ml}$ ) was diluted in $53.6 \mathrm{ml} \mathrm{NaCl} 0.9 \%$ to which $6 \mathrm{ml}$ albumen was added $(20 \%)$. Baseline measurements for hormones, blood pressure, heart rate and the symptom questionnaire were taken at $-30,-15$ and 0 min. At time $t=0$ an intravenous infusion of insulin with a syringe pump (ASID Bonz PP 50; Messer, Griesheim, Germany) was started for $480 \mathrm{~min}(50 \mathrm{mU} / \mathrm{kg}$ per h). Following $120 \mathrm{~min}$ of euglycaemia ( $4.0 \mathrm{mmol} / \mathrm{l})$ maintained by a variable glucose infusion ( $1.11 \mathrm{~mol} / \mathrm{l}$; Imed 928, Abingdon, Oxon, UK) the blood glucose level was gradually lowered within $30 \mathrm{~min}$ from 4.0 to $3.5 \mathrm{mmol} / \mathrm{l}$ and was maintained at that level for another $60 \mathrm{~min}$. This sequence of steps (i. e. a gradual fall of $0.5 \mathrm{mmol} / \mathrm{l}$ ) was repeated twice in the healthy volunteers until the glucose nadir of $2.5 \mathrm{mmol} / \mathrm{l}$ was attained. In the diabetic patients the clamp was extended by doubling of the insulin dose $(100 \mathrm{mU} /$ $\mathrm{kg}$ per h) to the step of $2.0 \mathrm{mmol} / \mathrm{l}$ (Fig. 1). Blood glucose levels were monitored every $2.5 \mathrm{~min}$ for the first hour of the test and every 5 min thereafter. Blood samples for later measurement of catecholamines, glucagon, growth hormone, cortisol and pancreatic polypeptide were taken at $90 \mathrm{~min}$ and every $15 \mathrm{~min}$ thereafter. Blood pressure and heart rate were measured automatically every 15 min during the test (Colin; Hayashi Komaki City, Japan). At intervals of $30 \mathrm{~min}$ the subjects were asked to complete a symptom questionnaire, where the symptoms related to hypoglycaemia were ranked on a linear analogue scale from $0=$ none to $6=$ very severe $[24,25]$. Symptoms such as warmness, palpitations, anxiety, tremor, sweating, shivering, hunger and blurred vision were considered as autonomic, whereas difficulty speaking, dizziness, weakness, double vision, tiredness, concentration problems, drowsiness and confusion were interpreted as neuroglycopenic. For the assessment of concentration, as one of the components of cognitive function during the test, at baseline and at each glucose level patients performed the Digit Span Forward and Backward test [28, 29] as a part of the modified and well-validated Wechsler Adult Intelligence Scale [30]. Scoring included the number of correct trials, starting with a sequence length of three, up to the point where two series of the same length were failed. To avoid a learning effect patients extensively trained on the evening before the clamp. A different list of digit series was employed at each glucose level. At the end of the study the patients filled in a questionnaire about the new therapeutic regimen. Throughout the test the subjects remained in a supine or semi-recumbent position and abstained from food, drink and smoking. They were not informed about their blood glucose value at any time of the test.

Analytical methods. During the clamp blood glucose was measured at bedside using a glucose oxidase method on a Yellow Springs glucose analyser (YSI 2300 STAT PLUS; Yellow

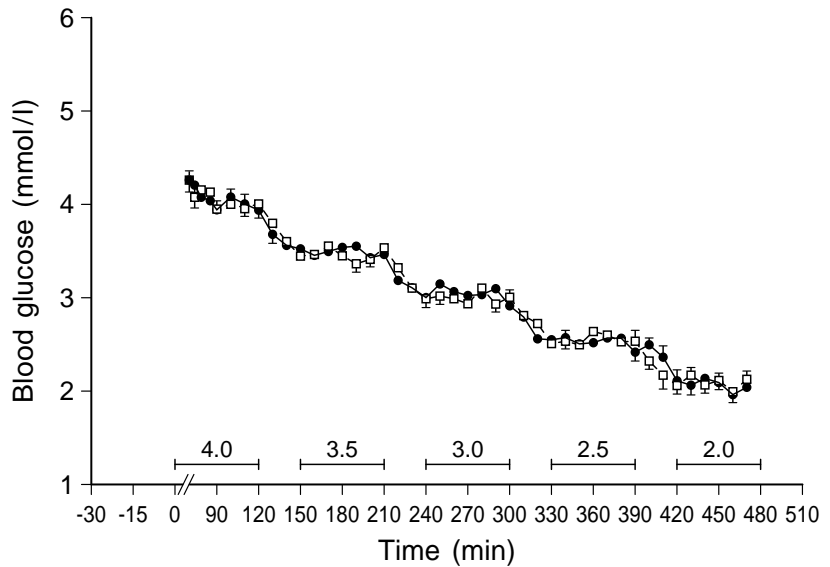

Fig. 1. Blood glucose (mean \pm SEM) in IDDM subjects during the euglycaemic-hypoglycaemic clamp test, following nighttime CSII ( $\bullet$ ) and bedtime NPH insulin treatment ( $\square$ )

Springs Instruments, Yellow Springs, Ohio, USA). Plasma catecholamines were measured by using high performance liquid chromatography (HPLC) with electrochemical detection as previously described [31]. Cortisol (Coat-A-Count, DPC, Los Angeles, Calif., USA), growth hormone (Sorin Biomedica; HGHK-2, Saluggia, Italy), pancreatic polypeptide (RIA developed in house by using antibodies raised in rabbits, labelled pancreatic polypeptide [Novo, Copenhagen, Denmark], SAC Cell [Wellcome, Dartford, UK] as precipitating second antibody) and plasma insulin (Medgenix, Fleurs, Belgium, for specific insulin, no cross-reactivity with proinsulin and split-products) using immunoassays. Insulin-antibody binding was measured by a fluid phase assay, using monoiodinated insulin and polyethylene glycol 6000 to separate bound from free radiolabelled [32]. When insulin antibodies were present, serum was pretreated with polyethylene glycol before analysis of insulin. Paired study samples were run in the same assay. Plasma glucagon measurement (Linco Research, St. Louis, Mo., USA) was modified by an ethanol extraction method to remove big-glucagon [33]. The samples for glucagon were collected in tubes containing EDTA and $250 \mathrm{KIU}$ of aprotinin (Trasylol; Bayer, Leverkusen, Germany). $\mathrm{HbA}_{1 \mathrm{c}}$ was measured by an HPLC method (range in non-diabetic subjects 4.3-6.1\%). Inter-assay coefficient of variation was not greater than $10 \%$ for any assay.

Statistical analysis. Data on subject characteristics are given as median and range. All other data are presented as mean \pm SEM. Glycaemic thresholds for counterregulatory hormone responses and hypoglycaemic symptoms were defined as a sustained elevation above the upper $95 \%$ confidence limit observed for that parameter during euglycaemia (the first $120 \mathrm{~min}$ of the test). Differences in glycaemic thresholds between both treatments were analysed by paired two-tailed $t$ tests. Differences in these parameters between each treatment group and the healthy subjects were analysed using unpaired two-tailed $t$-tests [34]. Results of the cognitive tests were analyzed by two-tailed $t$-tests comparing the mean score achieved at each glucose level with the baseline score for each treatment regimen respectively and comparing the change of scores at each glucose level between the two treatments. A commercially available software package (SPSS Microsoft, Redmond, Wash., USA, and SPSS for Windows) was used for statistical analysis. 
Table 2. Glycaemic thresholds for the activation of the counterregulatory hormones in healthy subjects and in subjects with IDDM treated with night-time CSII or NPH insulin at bedtime

\begin{tabular}{llll}
\hline Counterregulatory hormones & Healthy subjects & IDDM patients (CSII) & IDDM patients (NPH) \\
\hline Pancreatic polypeptide & $3.3 \pm 0.06$ & $2.7 \pm 0.2^{\mathrm{a}}$ & $2.6 \pm 0.2^{\mathrm{b}}$ \\
Growth hormone & $3.4 \pm 0.03$ & $3.1 \pm 0.2$ & $2.8 \pm 0.1^{\mathrm{a}, \mathrm{c}}$ \\
Epinephrine & $3.5 \pm 0.06$ & $2.9 \pm 0.2$ & $2.7 \pm 0.1^{\mathrm{a}}$ \\
Norepinephrine & $2.9 \pm 0.04$ & $2.5 \pm 0.2$ & $2.4 \pm 0.1^{\mathrm{a}}$ \\
Cortisol & $3.1 \pm 0.06$ & $2.2 \pm 0.1^{\mathrm{b}}$ & $2.3 \pm 0.1^{\mathrm{b}}$ \\
\hline
\end{tabular}

Data are mean \pm SEM $(\mathrm{mmol} / \mathrm{l})$

${ }^{\mathrm{a}} p<0.05$ vs healthy subjects; ${ }^{\mathrm{b}} p<0.01$ vs healthy subjects; ${ }^{\mathrm{c}} p<0.05$ vs IDDM subjects with CSII

\section{Results}

Glycaemic control and hypoglycaemic events. No differences in $\mathrm{HbA}_{1 \mathrm{c}}$ levels were observed between the end of the CSII and the end of the NPH period: $7.2 \pm 0.2$ vs $7.1 \pm 0.2 \%, p=0.2$. Total daily insulin requirements during the last week of the treatment period were significantly lower for CSII treatment than for NPH treatment: $48.0 \pm 3.7$ vs $56.4 \pm 4.9$ IU, $p=0.003$. Daytime short-acting insulin consumption before lunch and before dinner was significantly higher with CSII therapy than with NPH therapy: before breakfast $12.1 \pm 1.4$ vs $10.1 \pm 0.9 \mathrm{IU}, p=0.08$, before lunch $12.3 \pm 1.3$ vs $9.4 \pm 1.0 \mathrm{IU}, p=0.006$, before dinner $15.7 \pm 1.6$ vs $12.5 \pm 1.7 \mathrm{IU}, p=0.002$. The total number of hypoglycaemic episodes (i.e. blood glucose values $<3.5 \mathrm{mmol} / \mathrm{l}$ ) during the last 6 weeks of both treatment periods was significantly lower for CSII than for NPH treatment: $16.1 \pm 3.1$ vs $23.6 \pm 3.3, p=0.03$. The frequency of night-time hypoglycaemia during CSII and NPH therapy could not be compared because of the low number of nocturnal blood glucose levels actually measured. The frequency of fasting hypoglycaemia was not significantly different for CSII and NPH therapy: $2.6 \pm 1.3$ vs $5.5 \pm 1.5, p=0.2$. As a measure of the variability of nocturnal glycaemic excursions the standard deviations of the fasting glucose levels during the last 6 weeks of each treatment period were calculated. Fasting glucose levels were significantly less variable during CSII therapy than during NPH therapy: $3.1 \pm 0.2$ vs $3.9 \pm 0.3, p=0.009$.

Warning symptoms. During CSII 3 of 14 patients reported a change in the nature of the first warning symptom from neuroglycopenic to autonomic. In 8 patients during CSII and in all patients during NPH treatment the first symptom was neuroglycopenic. All but one patient reported that during CSII 'feeling low' occurred at a higher glucose level than on their usual treatment regimen.

Counterregulatory response. Glycaemic thresholds for the counterregulatory hormone responses are shown in Table 2. The growth hormone response was elicited at a significantly higher glucose level (i.e. at
Table 3. Change of Total Digit Span scores at hypoglycaemic levels compared to baseline performance and comparing both treatments. A positive score represents improvement, a negative score deterioration

\begin{tabular}{lrrrr}
\hline $\begin{array}{l}\text { Glucose } \\
\text { clamp values }\end{array}$ & $3.5 \mathrm{mmol} / \mathrm{l}$ & $3.0 \mathrm{mmol} / \mathrm{l}$ & $2.5 \mathrm{mmol} / \mathrm{l}$ & $2.0 \mathrm{mmol} / \mathrm{l}$ \\
\hline CSII & $-2.2 \pm 1.3$ & $-3.1 \pm 1.4^{\mathrm{b}}$ & $-3.6 \pm 1.4^{\mathrm{b}}$ & $-4.0 \pm 1.9$ \\
$\mathrm{NPH}$ & $0.1 \pm 1.0$ & $1.1 \pm 1.1^{\mathrm{a}}$ & $0.2 \pm 1.5$ & $-2.3 \pm 4.7$ \\
\hline
\end{tabular}

Data are mean \pm SEM

${ }^{\mathrm{a}} p<0.005$ vs IDDM subjects with CSII; ${ }^{\mathrm{b}} p<0.05$ vs baseline

a lower threshold) after CSII than after NPH treatment. The glucose thresholds for epinephrine, norepinephrine and glucagon were not significantly lower with CSII than with NPH treatment. The glucose thresholds for the counterregulatory responses during CSII did not differ significantly from the thresholds in healthy persons in the case of growth hormone, epinephrine and norepinephrine, but were significantly higher for pancreatic polypeptide and cortisol. During NPH the thresholds for all hormones were significantly higher than the thresholds in healthy persons. The glucagon response in healthy persons could not be included in the analysis due to differences in the assay method.

Symptoms. With CSII therapy the autonomic symptoms appeared earlier, thus at significantly higher blood glucose levels than after NPH therapy: $3.1 \pm 0.1 \mathrm{mmol} / 1$ vs $2.8 \pm 0.2 \mathrm{mmol} / 1, p=0.02$. No differences between CSII and NPH therapy were detected in the hypoglycaemic thresholds for neuroglycopenic symptoms: $3.4 \pm 0.06$ vs $3.1 \pm 0.1 \mathrm{mmol} / 1, p=0.2$.

Glucose requirements. Total glucose requirements during the clamps after CSII and NPH therapy were not statistically significantly different: $1697 \pm 120.7$ vs $1825.5 \pm 117.0 \mathrm{mg} / \mathrm{kg}$, NS.

Cognitive function. Following NPH treatment the scores of the Digit Span test at each hypoglycaemic level compared to the baseline score did not deteriorate significantly at any glucose level, whereas during CSII treatment a significant deterioration occurred at $3.0 \mathrm{mmol} / \mathrm{l}(p=0.034)$ and at $2.5 \mathrm{mmol} / \mathrm{l}(p=0.03)$. 

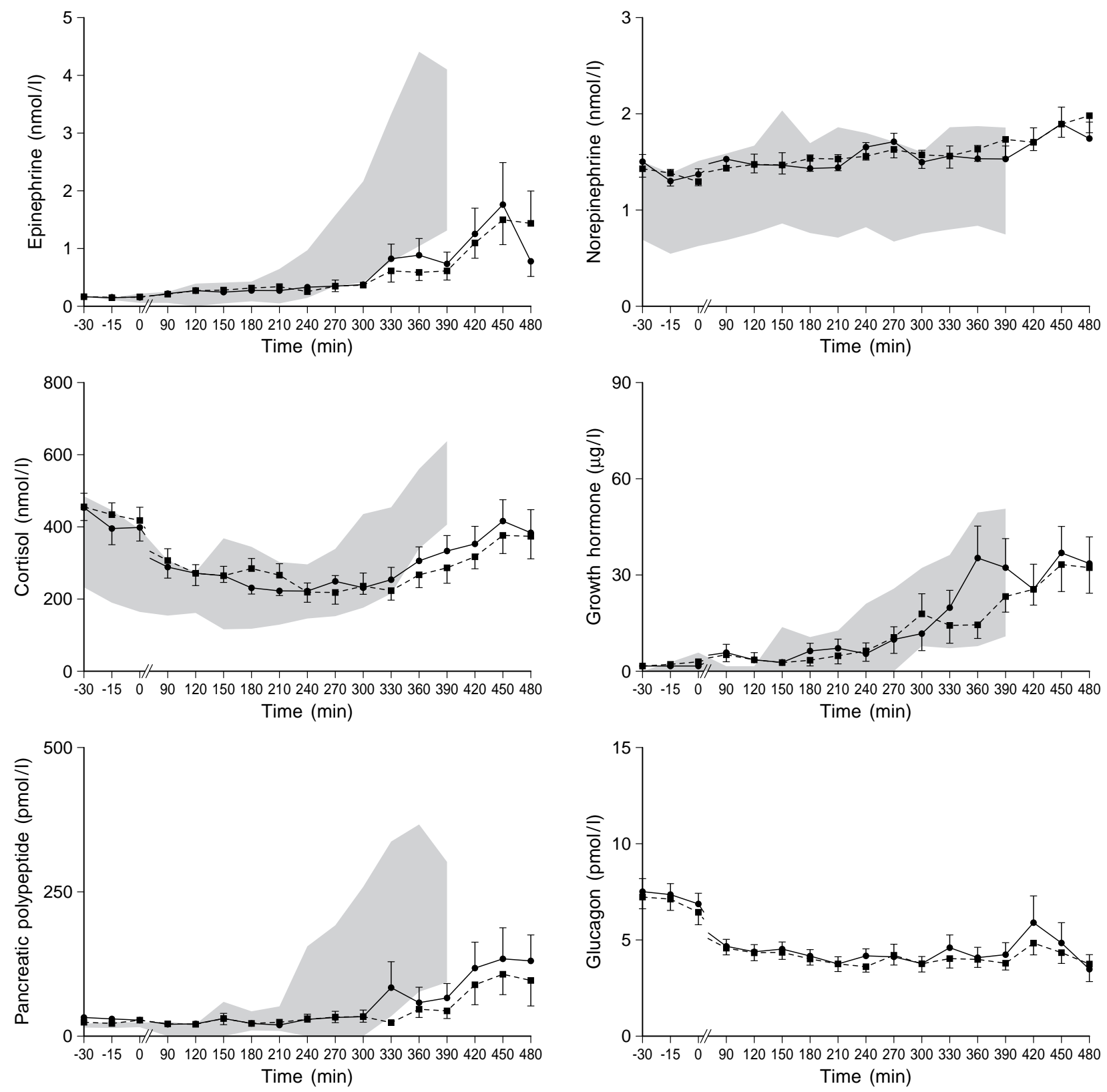

Fig. 2. Counterregulatory (CR) hormone responses (mean \pm SEM) in IDDM subjects during the euglycaemic-hypoglycaemic clamp test, following night-time CSII (๑) and bedtime NPH insulin treatment (ם). The shaded area represents the mean $\pm 1 \mathrm{SD}$ of $\mathrm{CR}$ hormone responses in healthy subjects. In 5 of 11 patients (following CSII and NPH) the measurement at 480 min was not performed since they were unable to tolerate the last $30 \mathrm{~min}$ of the test. The glucose nadir in healthy subjects was set at $2.5 \mathrm{mmol} / \mathrm{l}$

When comparing the total performance scores during the hypoglycaemic clamp between the two treatments, a significantly greater deterioration occurred in CSII at the glucose level of $3.0 \mathrm{mmol} / 1(p=0.004)$ (Table 4). Cognitive testing was not performed in healthy persons.

Acceptability. At the end of the study 6 of 14 patients decided on night-time CSII therapy combined with short-acting insulin during the day. Reported comments of these 6 patients were absence of night-time hypoglycaemia $(n=5)$, absence of fasting hypoglycaemia $(n=1)$, fewer episodes of hypoglycaemia during daytime $(n=4)$, loss of fear for hypoglycaemia $(n=3)$ and feeling 'low' at a higher glucose level than on their usual treatment regimen $(n=4)$. Main arguments from the 8 people who did not decide on CSII was the time-consuming preparation of the catheter in the evening, which in general took 5 to $10 \mathrm{~min}$. One patient reported that wearing the pump confronted him negatively with the notion of having diabetes. The pump did not disturb patients during sleep. A negative effect of the pump on sex life was reported by two patients. 


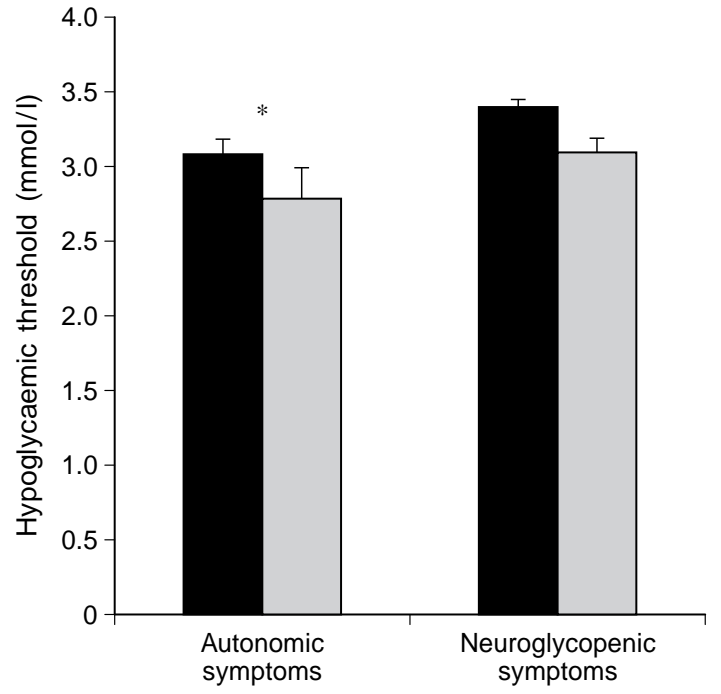

Fig. 3. Autonomic and neuroglycopenic symptom responses (mean \pm SEM) in IDDM subjects during the euglycaemic-hypoglycaemic clamp test, following night-time CSII ( $\square$ ) and bedtime insulin treatment $(\square)(* p<0.05)$

\section{Discussion}

The Diabetes Control and Complications Trial (DCCT) demonstrated that good glycaemic control confers a high risk of severe hypoglycaemia [4]. Since then several treatment strategies have been developed to diminish this risk. Our study demonstrates that the substitution of CSII for the bedtime NPH insulin injection in a multiple insulin injection therapy enhances the warning symptoms of hypoglycaemia as well as part of the counterregulatory hormonal response in well-controlled IDDM patients. Probably this effect is at least partly mediated by reducing the incidence of nocturnal hypoglycaemia. During nighttime CSII fasting blood glucose levels were found to be less variable than during NPH treatment. In addition, the total frequency of hypoglycaemia was reduced. Unfortunately no comparison of nocturnal hypoglycaemia could be made from the home blood glucose monitoring diaries, because the low number of weekly night-time measurements did not allow a reliable analysis.

Recurrent hypoglycaemia, including nocturnal hypoglycaemia, has been recognized as one of the major factors in the pathogenesis of hypoglycaemia unawareness [8-10, 35]. Studies in animals [36, 37] and humans [38] have demonstrated that recurrent hypoglycaemia induces an adaptation (i.e. upregulation of the glucose transporters ) of the central nervous system, allowing sufficient glucose from the circulation to be extracted for its normal functioning. Our study, in accordance with previous studies [17, 39, 40], suggests that the avoidance of hypoglycaemia results in an amelioration of the awareness of hypoglycaemia. In our study favourable results were accom- plished without a significant increase in $\mathrm{HbA}_{1}$, as in the study by Cranston et al. [39]. In two other studies, however, avoidance of hypoglycaemia was accompanied by some deterioration of glycaemic control [17, 40]. In these studies hypoglycaemia was prevented by vigorous adjustment of insulin dose, physical activity and eating pattern of the patients. This method requires intensive guidance by medical personnel and interferes with patients' normal lifestyle. Obviously such a method is quite difficult to apply in daily routine in a large patient population. Our treatment regimen was somewhat less time and energy consuming as we avoided nocturnal hypoglycaemia by applying a more predictable insulin delivery, i.e. night-time CSII, without altering patients' lifestyle. In our experience it was easy to find the appropriate infusion rate with CSII and the required increments of daytime regular insulin doses.

Schiffrin and Belmonte [41] reported a good patient acceptability of night-time CSII combined with multiple injections during daytime, notwithstanding the fact that their study was performed in a prepen-device era. In this early study hypoglycaemia was not addressed in detail. Using CSII only during the night automatically diminishes the likelihood of pump-related complications and avoids the daytime pump-related inconveniences. In our study only two patients reported interference with their sexlife and no patient complained about sleep disturbances. The time-consuming preparation of the pump was the most frequently reported disadvantage of nighttime CSII. In spite of this six patients decided to continue with night-time CSII. The benefit of avoiding nocturnal hypoglycaemia obviously needs to be balanced against the inconvenience on an individual basis.

During the stepwise lowering of the blood glucose levels cognitive function deteriorated earlier with CSII than with NPH insulin therapy. The rate of deterioration was similar to that reported in the studies of Fanelli et al. [17, 42] and is in agreement with the hypothesis of brain adaptation to hypoglycaemia [43]. In other studies, however, the avoidance of hypoglycaemia did not result in a change in the glucose level at which cognitive dysfunctioning occurred [39, 44]. This is probably due to different cognitive function tests applied and the lack of a hypoglycaemia-specific cognitive function test [45].

The growth hormone response was elicited at a significantly higher glucose level (i.e. at a lower threshold) after CSII than after NPH treatment. For the thresholds of the other hormones, although they appeared lower with CSII than with NPH, differences were not as striking as in some other studies. This may be attributable to the less stringent avoidance of hypoglycaemia $[17,39,42]$ and the longer duration of diabetes in our patients compared to those of Fanelli et al. [17], who included patients with a duration 
of diabetes of less than 7 years. It is remarkable that the thresholds of epinephrine and norepinephrine were not significantly different between CSII and $\mathrm{NPH}$, whereas the autonomic symptoms were experienced at higher glucose levels after CSII treatment. This is in line with results as reported by DagogoJack et al. [40]. It is likely that the recording of autonomic symptoms is more sensitive to changes in stimulation of the autonomic nervous system than the measurement of the corresponding hormone levels.

Taken together the clinically relevant results of this acute feasibility study with night-time CSII treatment include a lower incidence rate of hypoglycaemia, reversal of warning symptoms and improved response of some of the counterregulatory hormones, with maintenance of good glycaemic control. Moreover, this treatment was accepted well by the patients and could therefore represent an efficient and simple treatment strategy, suitable for a larger patient population. Simpler CSII devices could promote the applicability of this treatment even further.

Acknowledgements. We thank M. Aarsen, S. Casteleijn, A. van Iperen and E. Pinxter for their skilful technical assistance and the staff of the endocrine laboratory for the hormone measurements. We also thank the psychologist J. Lindeboom, Ph.D. for reviewing the manuscript, K. Nasseri, M.D. for performing the autonomic neuropathy tests and J.M. Molenaar, Ph.D. for the measurements of insulin antibodies. We are indebted to Diabetes Fonds Nederland for financial support. We very much thank the patients for their enthusiastic participation.

\section{References}

1. Reichard P, Nilsson BY, Rosenqvist U (1993) The effect of long-term intensified insulin treatment on the development of microvascular complications of diabetes mellitus. $\mathrm{N}$ Engl J Med 329: 304-309

2. Wang PH, Lau J, Chalmers TC (1993) Meta-analysis of effects of intensive blood-glucose control on late complications of type 1 diabetes. Lancet 341: 1306-1309

3. The Diabetes Control and Complications Trial Research Group (1993) The effect of intensive treatment of diabetes on the development and progression of long-term complications in insulin-dependent diabetes mellitus. N Engl J Med 329: 977-986

4. The DCCT Research Group (1991) Epidemiology of severe hypoglycaemia in the Diabetes Control and Complications Trial. Am J Med 90: 450-459

5. Amiel SA, Tamborlane WV, Simonson DC, Sherwin RS (1987) Defective glucose counterregulation after strict glycemic control of insulin-dependent diabetes mellitus. N Engl J Med 316: 1376-1383

6. Amiel SA, Sherwin RS, Simonson DC, Tamborlane WV (1988) Effect of intensive insulin therapy on glycemic thresholds for counterregulatory hormone release. Diabetes 37: 901-907

7. Lingenfelser T, Renn W, Sommerwerck U, et al. (1993) Compromised hormonal counterregulation, symptom awareness, and neurophysiological function after recurrent short-term episodes of insulin-induced hypoglycemia in IDDM patients. Diabetes 42: 610-618
8. Frier BM (1993) Hypoglycaemia unawareness. In: Frier BM, Fisher M (eds) Hypoglycaemia and diabetes. Edward Arnold, Sevenoaks, UK pp 284-301

9. Gerich JE, Mokan M, Veneman T, Korytkowski M, Mitrakou A (1991) Hypoglycemia unawareness. Endoc Rev 12: 356-371

10. Veneman T, Mitrakou A, Mokan M, Cryer PE, Gerich J (1993) Induction of hypoglycaemia unawareness by asymptomatic nocturnal hypoglycemia. Diabetes 42: 1233-1237

11. Thow JC, Home PD (1993) Nocturnal hypoglycaemia. In: Frier BM, Fisher M (eds) Hypoglycaemia and diabetes. Edward Arnold, Sevenoaks, UK pp 284-301

12. Bolli GB, Perriello G, Fanelli CG, De Feo P (1993) Nocturnal blood glucose control in type I diabetes mellitus. Diabetes Care 16 [Suppl 3]:71-89

13. Heine RJ (1993) Insulin therapy. In: Home PD, Marshall SM, Alberti KGMM, Krall LP (eds) The Diabetes Annual 1 7. Elsevier, Amsterdam, pp 284-302

14. Lauritzen T, Pramming S, Gale EAM, Deckert T, Binder C (1982) Absorption of isophane (NPH) insulin and its clinical implications. BMJ 285: 159-162

15. Bilo HJG, Heine RJ, Sikkenk AC, van der Meer J, van der Veen EA (1987) Absorption kinetics and action profiles of intermediate acting human insulins. Diabetes Res 4: 39-43

16. Perriello G, De Feo P, Torlone E, et al. (1990) Nocturnal spikes of growth hormone secretion cause the dawn phenomenon in type 1 (insulin-dependent) diabetes mellitus by decreasing hepatic (and extrahepatic) sensitivity to insulin in the absence of insulin waning. Diabetologia 33: 52-59

17. Fanelli CG, Epifano L, Rambotti AM, et al. (1993) Meticulous prevention of hypoglycemia normalizes the glycemic thresholds and magnitude of most neuroendocrine responses to, symptoms of, and cognitive function during hypoglycemia in intensively treated patients with short-term IDDM. Diabetes 42: 1683-1689

18. Binder C, Lauritzen T, Faber O, Pramming S (1984) Insulin pharmacokinetics. Diabetes Care 3: 188-199

19. Lauritzen T, Pramming S, Deckert T, Binder C (1983) Pharmacokinetics of continuous subcutaneous insulin infusion. Diabetologia 24: 326-329

20. Olsson PO, Arnqvist H, von Schenck H, Ottoson AM (1987) Overnight metabolic control with bedtime injection of intermediate-acting insulin or continuous subcutaneous insulin infusion. Diabetes Care 10: 702-706

21. Hirsch IB, Farkas-Hirsch R, Cryer PE (1991) CSII for the treatment of diabetic patients with hypoglycemia unawareness. Diab Nutr Metab 4: 41-43

22. Koivisto VA, Yki-Järvinen H, Helve E, Karonen SL, Pelkonen R (1986) Pathogenesis and prevention of the dawn phenomenon in diabetic patients treated with CSII. Diabetes 35: 78-82

23. Ewing DJ, Clarke BF (1982) Diagnosis and management of diabetic autonomic neuropathy. BMJ 285: 916-918

24. Jacobs MAJM, Salobir B, Popp-Snijders C, Ader H, Heine RJ (1997) Counterregulatory hormone responses and symptoms during hypoglycaemia induced by porcine, human regular insulin, and Lys(B28), Pro(B29) human insulin analogue (insulin lispro) in healthy male volunteers. Diabet Med 14: 248-257

25. Hepburn DA, Deary IJ, Frier BM, Patrick AW, Quin JD, Fisher BM (1991) Symptoms of acute insulin-induced hypoglycaemia in humans with and without IDDM. Factoranalysis approach. Diabetes Care 14: 949-957

26. Heine RJ (1993) Methods of investigation of insulin-induced hypoglycaemia. In: Frier BM, Fisher BM (eds) Hypoglycaemia and diabetes. Edward Arnold, Sevenoaks, UK, pp 165-175 
27. Liu D, Moberg E, Kollind K, Lins P-E, Macdonald IA (1992) Arterial, arterialised venous, venous and capillary blood glucose measurements in normal man during hyperinsulinaemic euglycaemia and hypoglycaemia. Diabetologia 35: 287-290

28. Wechsler D (1981) WAIS-R manual. Psychological Corporation, New York

29. Willems PJ, Coetsier P, Hulsman WLL (1970) Handleiding bij de nederlandstalige bewerking van de Wechsler Adult Intelligence Scale, WAIS, Swets en Zeitlinger, Amsterdam

30. Lindeboom J, Matto D (1994) Cijferreksen en Knox blokken als concentratietests voor ouderen (Digit span and the Knox cube test as concentration tests for the elderly). Tijdschrift Gerontol Geriat 25: 63-68

31. Popp-Snijders C, Geenen B, van der Heijden EAP (1989) Serum noradrenaline is composed of plasma and platelet noradrenaline. Ann Clin Biochem 26: 191-192

32. Snorgaard O, Kjems LL, Røder ME, Hartling SG, Dinesen B, Binder C (1996) Proinsulin immunoreactivity in recentonset IDDM. Diabetes Care 19: 146-150

33. Nooijen WJ, Koppert PW (1981) Radioimmunoassay for pancreatic glucagon based on specific derivatization of the hormone. Ann Clin Biochem 18: 118-122

34. Altman DG (1991) Comparing groups-continuous data. In: Altman DG (ed) Practical statistics for medical research. Chapman and Hall, London, UK pp 179-223

35. Cryer PE (1992) Iatrogenic hypoglycemia as a cause of hypoglycemia associated autonomic failure in IDDM: a vicious cycle. Diabetes 41: 255-260

36. Biggers DW, Myers SR, Neal D, et al. (1989) Role of the brain in counterregulation of insulin induced hypoglycemia in dogs. Diabetes 38: 7-16
37. McCall AL, Fixman LB, Fleming N, Tornheim K, Chick W, Ruderman NB (1986) Chronic hypoglycaemia increases brain glucose transport. Am J Physiol 251:E442-E447

38. Boyle PJ, Kempers SF, O'Connor AM, Nagy RJ (1995) Brain glucose uptake and unawareness of hypoglycemia in patients with insulin-dependent diabetes mellitus. N Engl J Med 333: 1726-1731

39. Cranston I, Lomas J, Maran A, Macdonald I, Amiel SA (1994) Restoration of hypoglycaemia awareness in patients with long-duration insulin-dependent diabetes. Lancet 344: 283-287

40. Dagogo-Jack S, Rattarasarn C, Cryer PE (1994) Reversal of hypoglycaemia unawareness, but not defective glucose counterregulation, in IDDM. Diabetes 43: 1426-1434

41. Schiffrin A, Belmonte M (1981) Combined continuous subcutaneous insulin infusion and multiple subcutaneous injections in type 1 diabetic patients. Diabetes Care 4: 595-600

42. Fanelli C, Pampanelli S, Epifano L, et al. (1994) Long-term recovery from unawareness, deficient counterregulation and lack of cognitive dysfunction during hypoglycaemia, following institution of rational, intensive insulin therapy in IDDM. Diabetologia 37: 1265-1276

43. Kumagai AK, Kang Y-S, Boado RJ, Pardridge WM (1995) Upregulation of blood-brain barrier GLUT 1 glucose transporter protein and mRNA in experimental chronic hypoglycemia. Diabetes 44: 1399-1404

44. Widom B, Simonson DC (1990) Glycemic control and neuropsychologic function during hypoglycemia in patients with insulin-dependent diabetes mellitus. Ann Int Med 112: 904-912

45. Dagogo-Jack S (1994) Commentary. Diabetes Spectrum 7: $256-257$ 